


\title{
PUPILS' DRAWINGS OF WHAT IS INSIDE THEMSELVES: A CASE STUDY IN ZIMBABWE
}

\author{
Viola Manokore \\ Science and Maths Education, University of Zimbabwe \\ and \\ Michael J. Reiss \\ University of London, Institute of Education
}

\section{Abstract}

This preliminary study looks at the understandings, as revealed by their drawings, of some seven-year-olds and 15-year-olds in Zimbabwe of their internal anatomy. A total of 23 seven year-olds and 21 fifteen year-olds participated in the study. These pupils were given a blank piece of A4-sized (296 $x 210 \mathrm{~mm}$ ) drawing paper and asked to draw what they thought was inside themselves. -The drawings were analysed on a seven point scale related to biological knowledge of human organs and organ systerns. The results show that the older pupils had a greater knowledge of their internal anatomy but that there was no relationship between gender and biological knowledge. Some organ systems - the gaseous exchange system, the digestive system, the circulatory system, the skeletal system, the urinogenital system and the nervous system, were statistically more likely to have organs drawn from them than were others such as the endocrine system and the muscular system. Recommendations are made for biology teaching which would help improve understanding in this area. In particular, when introducing human anatomy to pupils, teachers could begin with individual organs and then help pupils appreciate that these organs exist as functional units within organ systems. This could be done by the use of three-dimensional models or by assembling two-dimensional organ systems from cut organ system diagrams.

\section{Introduction}

In this study we look at a sample of pupils in Zimbabwe who reveal through drawings what they know about their internal structure. As far as pupils' knowledge, as revealed by drawings, of what is inside themselves goes, the most studied organ system is the skeleton (Caravita \& Tonucci, 1987; Guichard, 
1995; Cox, 1997; Tunnicliffe \& Reiss, 1999a). Those research reports and papers that have looked at other organ systems have often reported valuable data (notably Gellert, 1962; Goldman \& Goldman, 1982; Johnson \& Wellman; 1982; Mintzes, 1984; Carey, 1985; Williams, Wetton \& Moon, 1989; Osbome, Wadsworth \& Black, 1992; Teixeira, 1998; Selles \& Ayres, 1999) but there is very little work that systematically and quantitatively examines how knowledge, as revealed by drawings, of the various human organs and organ systems depends on pupil age. In addition, we have been unable to find any such work that has been conducted in Zimbabwe.

With this background, the main aim of this study was to uncover Zimbabwean pupils' understandings of human organs and organ systems as revealed by drawings. The specific objectives of the study were to find out:

- the relationship between pupil age and the biological understanding revealed by the drawings;

- the relationship between pupil gender and the biological understanding revealed by the drawings;

pupils' understanding of entire organ systems;

pupils' understanding of organs.

\section{Methodology}

\section{Design}

It has been acknowledged that there are many ways of gathering information about pupils' understandings of scientific phenomena (White \& Gunstone, 1992; Tünicliffe \& Reiss, 1999a). Most methods used by science educators to solicit information from pupils rely on pupils talking or writing about science. Such methods include the oral interviewing of pupils (Osborne \& Gilbert, 1980), gathering pupils' written responses (Leach, Driver, Scott \& Wood-Robinson, 1995), recording pupils' spontaneous conversations (Tunnicliffe \& Reiss, $1999 b$ ) and getting pupils to construct written concept maps (Novak \& Musonda, 1991).

Each research approach has its own advantages and disadvantages. In this study, a method which relied less on words, namely drawings, was used to gather information about pupils' understanding of human internal systems. Unlike other approaches which rely on words, this method is less likely to 
disadvantage pupils who are shy in conversation, pupils who lack certain linguistic skills and pupils who speak English as a second language. In Zimbabwe, it is widely believed that most pupils lack certain linguistic skills to enable them to understand certain scientific phenomena. As a result, some pupils have problems expressing scientific concepts using English words. The researchers were not interested in the artistic.merits of pupils' drawings but in what was revealed as far as their understanding of human organs and organ systems was concerned.

Elsewhere it has been argued that there may be no such single thing as a person's 'understanding', different aspects of which can be revealed by different methodologies (Reiss \& Tunnicliffe [in press]). Instead, it may be that different methodologies reveal different things about the multi-dimensional complexity usually labelled 'understanding' but better recognised as 'understandings'. On this reasoning, drawings are used in this study to reveal a view of certain aspects of each pupil's understandings.

\section{Study Area and Population}

Fieldwork was carried out in Harare North, Mount Pleasant area. Drawings by 15 year-olds were done by pupils from a high school; those done by 7 -yearolds came from a primary school. Data were collected at the beginning of the first school term in the year 2000 .

By the time they reached Form 3, the 15-year-olds would have covered topics on digestion, reproduction, and respiratory (gaseous exchange) systems during science lessons. The class which participated had 37 pupils: 17 boys and 20 girls. The whole class made their drawings of what they thought was inside themselves and only drawings from the 15-year-olds were analysed. A total of 13 girls and 8 boys met the selection-criteria used.

At the primary school, the class which participated had 43 pupils: 21 girls and 22 boys. The pupils were in their second year of their primary school education, that is grade two. The pupils were studying the following subjects: Mathematics, English, Physical Education, Environmental Science and Shona. When the drawings were collected, the pupils had not done anything on human organs and organ systems. The whole class made the drawings of what they thought was inside themselves, and only drawings from the seven-year-olds were analysed. A total of 14 girls and 9 boys met the selection criteria. 


\section{Procedure}

Cox (1989) discusses some of the ways in which children can be asked to do drawings. In this study the pupils, in a whole class setting, were asked to draw what they thought was inside themselves. The pupils were not under formal examination conditions, but were told not to copy one another's work. They were given as long as they wanted to complete their drawing (up to 15 minutes) and were asked to write their name, age, and sex on the paper with their drawing. Pupils labelled their drawing, if they wanted to do so, in any language. Pupils who asked if they could label their drawings were told to do so if they wanted. Some seven-year-olds asked how to spell certain words and were helped as per request. This study is part of an on-going international one. Biology educators from around the world (generally just one per country) have been approached and invited to participate in the study. Once they have accepted, they are e-mailed or posted a detailed 12-item protocol which provides them with the research instrument (Appendix 1). This instrument had been trialled and developed in earlier work in the UK (Tunnicliffe \& Reiss, 1999a).

\section{Data Analysis}

A total of 44 drawings were analysed, ranking them in an order which reflected different levels of biological understanding. Our ranking built on previous work in the field - as described by Osborne, Wadsworth \& Black (1992), Guichard (1995) and Cox (1997) - and also used the researchers' knowledge of human anatomy. It is the same as that used by Reiss \& Tunnicliffe (in press) and strives to maximise reliability and validity. The scoring system does not consider the 'artistic' quality of the drawing or the pupil's age. Rather, it is bašed solely on the biological quality of each drawing as indicated in Figure 1.. The scoring system in Figure 1 requires a definition of organ systems. We used the definitions for eight human organ systems shown in Figure 2. Making explicit these definitions increases the objectivity of the scoring.

Having agreed on the level (i.e., 1-7) for the drawing, the drawing was then - scored as to whether or not it met the criterion for each of the eight organ systems. If it did, we recorded the appropriate capital letter ( $S$ for skeletal, $G$ for gaseous exchange, etc.). If it did not, we then decided whether or not at least one organ was present on the drawing for that organ system. If one was, we recorded the appropriate lower case letter ( $s$ for skeletal, $g$ for gaseous exchange, etc.). All rankings and scorings were undertaken by the authors. In the minority of instances where we differed, we discussed the differences until we reached agreement. 
To illustrate our analysis, Figure 3 shows a drawing by one of the female 15year-olds. It is scored $4 g d u c$. In other words, the drawing in Figure 3 shows no satisfactory organ systems (as defined in Figure 2) but contains organs in the following four organ systems: gaseous exchange, digestive, urinogenital, and circulatory.

All statistical tests are two-tailed.

\section{Results}

The results are presented under four headings, each relating to one of the research questions:

- the relationship. between pupil age and the biological understanding revealed by the drawings;

- the relationship between pupil gender and the biological understanding revealed by the drawings;

pupils' understanding of entire organ systems;

- pupils' understanding of organs.

The Relationship Between Pupil Age and the Level of the Drawing

Table 1: The Levels Attained by Pupils of Different Ages When Drawing Themselves

\begin{tabular}{ccccc} 
Age (years) & Mean level Median level & sem & n \\
\hline 7 & 1.52 & 2 & 0.11 & 23 \\
15 & 4.24 & 4 & 0.10 & 21 \\
\hline
\end{tabular}

Note: Levels equate to the 1-7 scale for understanding as described in the text. sem is the standard error of the mean; $n$ is the number of pupils in each age category.

As one would expect, the 15-year-olds attained higher levels than did the 7year-olds. Table 1 shows how the mean level attained increases when pupils are drawing themselves from 1.52 for the 7-year-olds to 4.24 for the 15-yearolds. This difference is highly significant $(t=19.0 ; p<<0.001)$. The median level increases from 2 to 4 . 
Viola Manokore and Michael Reiss

The Relationship Between Pupil Gender and the Level of the Drawing

Table 2 .

Analysis of Differences in the Levels Attained by Males and Females Within Age Groups

\begin{tabular}{|c|c|c|c|c|}
\hline$\overline{\text { Age }}$ & $\begin{array}{l}\text { Mean level } \\
\text { (years)for female }\end{array}$ & $\begin{array}{l}\text { Mean level } \\
\text { es for males }\end{array}$ & $\bar{t}$ & df \\
\hline 7 & 1.57 & 1.44 & 0.58 & 21 \\
\hline 15 & 4.23 & 4.25 & 0.10 & 19 \\
\hline
\end{tabular}

Table 2 provides the relevant parameters for males and females separately within year classes. There are no statistically significant gender differences: for 7 year-olds, $t=0.58, \mathrm{df}=21, \mathrm{p}>0.5$; for 15 year-olds, $\mathrm{t}=0.10, \mathrm{df}=19, \mathrm{p}>0.5$.

\section{Pupils' Understandings of Organ Systems}

None of the 23 seven-year-olds produced drawings that showed an entire organ system as defined in Figure 2. This is hardly surprising. However, what is perhaps more noteworthy is that of the 21 fifteen-year-olds, 16 produced drawings that showed no entire organs systems, five produced drawings that showed one organ system and none produced drawings that showed two or more organ systems. The five drawings with an organ system were produced by two males - both of whom drew the gaseous exchange system as defined in Figure 2 - and three females - all three of whom drew the skeletal system as defined in Figure 2. 


\section{Pupils' Understandings of Organs}

\section{Table 3}

Drawings of Organs by the Seven-year-olds $(n=23)$

\begin{tabular}{|c|c|c|}
\hline Organ & Number of drawing & $s \%$ of drawings \\
\hline $\begin{array}{l}\text { system } \\
\quad \text { organ system }\end{array}$ & $\begin{array}{c}\text { with an organ in this } \\
\text { organ system }\end{array}$ & with an organ in this \\
\hline Skeletal & 4 & $17 \%$ \\
\hline Gaseous exchange & 0 & $0 \%$ \\
\hline Nervous & 4 & $17 \%$ \\
\hline Digestive & 2 & $9 \%$ \\
\hline Endocrine & 0 & $0 \%$ \\
\hline Urinogenital & 1 & $4 \%$ \\
\hline Muscular & 0 & $0 \%$ \\
\hline Circulatory & 10 & $43 \%$ \\
\hline
\end{tabular}

Not surprisingly, pupils do much better at drawing organs than they do at drawing organ systems. Table 3 shows the number (and percentages) of the drawings produced by the seven-year-olds that show organs in each of the eight organ systems. The organ system that most frequently has an organ drawn is the circulatory system.

\section{Table 4}

Drawings of Organs by the 15-year-olds $(n=21)$

\begin{tabular}{|c|c|c|c|c|c|c|}
\hline \multirow{2}{*}{ Organ } & \multicolumn{6}{|c|}{ Number of drawings $\%$ of drawings } \\
\hline & $\begin{array}{l}\text { with an organ in this } \\
\text { organ system }\end{array}$ & $\begin{array}{l}\text { with } \\
\text { organ }\end{array}$ & $\begin{array}{c}\text { an } \\
\text { system }\end{array}$ & organ & in & this \\
\hline Skeletal & 9 & & $43 \%$ & & & \\
\hline Gaseous exchange & 18 & & & $86 \%$ & & \\
\hline Nervous & 7 & & & $33 \%$ & & \\
\hline Digestive & 12 & & & $57 \%$ & & \\
\hline Endocrine & 0 & & $0 \%$ & & & \\
\hline Urinogenital & 11 & & $52 \%$ & & & \\
\hline Muscular & 2 & & & $10 \%$ & & \\
\hline Circulatory & 4 & & $19 \%$ & & & \\
\hline
\end{tabular}


Table 4 shows the number (and percentages) of the drawings produced by the 15-year-olds that show organs in each of the eight organ systems. For this age group, the organ system that most frequently has an organ drawn is the gaseous exchange system, followed by the digestive system and then the urinogenital system. There is a statistically significant difference between the likelihood of pupils drawing organs from the different organ systems $\left(c^{2}=22.97,7\right.$ df, $p<0.001$ ). The differences between the 7-year-olds (Table 3 ) and the 15year-olds (Table 4) in terms of what they are most likely to draw is noteworthy.

\section{Discussion}

In this study pupils expressed themselves only through their drawings (some of which were labelled) rather than, for example, also being observed in class or interviewed. We did not require pupils to label their drawings - pupils who wished to label did so in any language of their choice. Nor did we use terms such as organs and organ systems in our instructions to them. For these reasons, the drawings, while they reflect pupil knowledge, also reflect their interest in the task and even their assumptions about what we wanted to see.

\section{The Importance of Student Age}

When the drawings are analysed by age, it is evident that 15 -year-olds achieve significantly higher levels, on our scoring system, than do 7-year-olds. This is as expected, both from the findings of other researchers, in particular Gellert (1962) in the USA and Reiss and Tunnicliffe (in press) in England, and from common sense. For one thing, quite apart from the fact that we would expect 15-year-olds to know the names of more of their internal organs than 7-yearolds, even if the 7-year-olds knew they had certain organs (e.g. a liver), it is unlikely that they would ever have seen a picture of them and so able to draw them.

Most of the 7-year-olds' drawings were not labelled and, on occasions, it was not clear which organ they were trying to represent. For example; one 7-yearold girl drew a circle with some fruits in it and then labelled it "stomach". Had the organ not been labelled, the researchers would not have been able to score it as representing an organ in the digestive system. For this reason, our scoring system will have underestimated the levels of the drawings done by some seven-year-olds. This will have been less of a problem with the drawings of the 15 -year-olds as here it was easier to see what even unlabelled organs were representing. 


\section{Zimbabwe Journal of Educational Research}

Pupils included some non-anatomical features in their drawings. Some sevenyear-olds drew and labelled food inside themselves, three boys drew cars and two pupils (one boy and one girl) wrote "Jesus".

\section{The Importance of Gender}

In this study there was no relationship between gender and biological understanding as revealed by the drawings.

\section{Pupils' Drawings of Organ Systems and Organs}

None of the 7-year-olds produced a drawing showing an entire organ system as defined in Figure 2. This is not surprising because, by the time they are in grade two, pupils have not yet studied human anatomy in school. The 15-yearolds who participated in the study had covered topics on digestion, reproduction, and gaseous exchange during their science lessons. However, despite the school biology they had received, few of these pupils demonstrated any knowledge of entire organ systems. Biology educators would like pupils not only, by the time they leave school, to have a good knowledge of their various organ systems (i.e. to be at level 6 or 7 on our scoring system) but also to appreciate the interconnections and interrelations of the various organ systems.

Most pupils drew isolated organs rather than organ systems. Between them, the seven-year-olds drew organs from five of the eight organ systems (Table 3 ). The organ system that most frequently had an organ drawn by the sevenyear-olds was the circulatory system. The seven-year-olds who drew a part of the circulatory system typically drew a heart as shaped on Valentine's cards. The two other organ systems that had organs drawn by the seven-year-olds in more than $10 \%$ of the drawings were the skeletal and the nervous systems. These results are similar to those of Gellert (1962) and Reiss \& Tunnicliffe (in press) who found that bones and hearts were the organs young children most often knew about. In this study the only pupil who drew an organ in the urinogenital system drew a kidney. Although it was not recognisable as a kidney, it was labelled appropriately in Shona.

The 15-year-olds drew organs from seven of the eight organ systems - the endocrine system, as defined in Figure 2, being the one organ system that never had any part of it drawn. By way of contrast with the seven-year-olds, the organ systems that most frequently had an organ drawn by the 15-yearolds were the gaseous exchange system followed by the digestive system (Table 4). Statistical analysis showed a significant tendency for some organ 


\section{Viola Manokore and Michael Reiss}

systems to be more, likely to have organs from them drawn than others. The fact that in this study 15-year-olds are most likely to draw organs from the gaseous exchange and digestive systems is presumably related to the fact that, along with the reproductive system, it is these systems that the pupils had studied in their recent schooling. Similarly, it is likely that the high frequency in Gellert's (1962) study of pupils who mentioned organs in the urinary system (39 out of 96 children) connects with the fact that these children were in hospital with many of them suffering from disorders. of the urinogenital system (Reiss \& Tunnicliffe [in press]).

\section{Conclusions and Recommendations}

This study shows that pupils' understandings of human organs and organ systems, as revealed by their drawings, increases with age. This is not surprising as older children will have come across more internal human anatomy in their biology or general science lessons and in out-of-school learning situations.

Some organ systems were much more likely to have organs drawn from them than others. The seven-year-olds were most likely to draw the heart whereas lungs and other parts of the gaseous exchange system were most likely to be drawn by the 15 -year-olds. Gender, though, appeared to have no relation to the biological knowledge revealed by the drawings.

The drawings analysed in this paper came only from a small sample, namely from two schools in Mount Pleasant, and generalisations cannot therefore be made to the education system throughout Zimbabwe. More work needs to be done with a larger, representative sample size.

Nevertheless, the fact that the 15 year-olds in this study drew organs from organ systems that they had been taught about shows that pupils are learning from their school biology lessons. However, there is also the suggestion that the science curriculum is not building upon and extending the knowledge that pupils bring to their science lessons. The fact that 7 year-olds know most about the circulatory system means that it would be beneficial if the biology curriculum started by teaching about the circulatory system before introducing less familiar systems.

In both age groups, pupils often drew organs well but rarely drew entire organ systems. This suggests to us that when introducing human anatomy to pupils, science educators would probably do well if they began with individual organs 
and then helped pupils appreciate that these organs exist as functional units within organ systems. This could be done by the use of three-dimensional models or by assembling two-dimensional organ systems from cut organ system diagrams.

A further aim, with older pupils, would be to enable them to appreciate the way in which the various organ systems interact. For example, in order for pupils to use their muscles to run, they not only need to use the components of the muscular system, the muscles need to be supplied with blood (circulatory system), to be attached to bones via tendons (skeletal system), to be controlled by nerves (nervous system), to have an enhanced supply of oxygen (gaseous exchange system) and so on. It is to be hoped that such teaching would not only be enjoyable for pupils but would help them to see their insides not as a scattered assemblage of individual organs but as a set of connected and functionally interrelating organ systems.

\section{References}

Caravita, S. \& Tonucci, F. (1987). How children know biological structure-function relationships. Paper presented at the Second International Seminar: Misconceptions and Educational Strategies in Science and Mathematics, Cornell University, Ithaca, New York.

Carey, S. (1985). Conceptual change in childhood. Cambridge, Massachusetts: Massachusetts Institute of Technology.

Cox, M. (1989). Children's drawings. In D. J. Hargreaves (Ed.), Children and . the arts (pp. 43-58). Buckingham, England: Open University Press.

Cox, M. (1997). Drawings of people by the under-5s. London: Falmer Press.

Gellert, E. (1962). Children's conceptions of the content and functions of the human body. Genetic Psychology Monographs, 65, 293-405.

Goldman, R. \& Goldman, J. (1982). Children's sexual thinking: A comparative study of children aged 5 to 15 years in Australia, North America, Britain and Sweden. London: Routledge \& Kegan Paul.

Guichard, J. (1995). Designing tools to develop the conception of learners. International Journal of Science Education, Vol. 17, pp. 243-253.

Johnson, C. N., \& Wellman, H. M. (1982). Children's developing conceptions of the mind and brain. Child Development, 53, 222-234. 
Leach, J, Driver, R., Scott, P. \& Wood-Robinson, C. (1995). Children's ideas about ecology 1: Theoretical background. design and methodology. Interna tional Journal of Science Education, 17, 721-732.

Mintzes, J: J. (1984). Naive theories in biology: Children's concepts of the human body. School Science and Mathematics, 84, 548-555:

Novak, J. D. \& Musonda, D. (1991). A twelve-year longitudinal study of science concept learning. American Educational Research Journal, 28,117-153.

Osborne, J., Wadsworth, P.\& Black, P. (1992). Processes of life: Primary space project research report. Liverpool, England: Liverpool University Press.

Osborne, R. J. \& Gilbert, J. K. (1980). A technique for exploring students' views of the world. Physics Education, 15; 376-379:

Rəiss, M. J. \& Tunnicliffe, S. D. (in press). Students' understandings of human organs and organ systems. Research in science education.

Selles, S. E., \& Ayres, A. C. B. M. (1999). Children's representations of digestive system from a model-based teaching learning perspective. Paper presented at the Second International Conference of the European Science Education Research Association, University of Kiel, Kiel, Germany.

Teixeira, F. M. (1998). What happens to the food we eat? Children's conceptions of the structure and function of the digestive system. Paper presented at the Conference of European Researchers in Didaktik of Biology, University of Göteborg, Sweden.

Tunnicliffe, S. D. \& Reiss, M. J. (1999a). Students' understandings aboü animal skeletons. International Journal of Science Education, 21, 1187-1200.

Tunnicliffe, S. B.\& Reiss, M. J. (1999b):-Building a model of the environment: How do children see animals? Journal of Biological Education, 33, 142-148.

White, R. T. \& Gunstone, R. F. (1992). Probing understanding. London: Falmer Press.

Williams, T:, Wetton, N: \& Moon,A. (1989). A Picture of health; What do you do that makes you healthy and keeps you healthy? London: Health Education Authority.

Level. 1 No representation of internal structure 


\section{Zimbabwe Journal of Educational Research}

Level 2 One or more internal organs (e.g. bones and blood) placed at random

Level 3 One internal organ (e.g. brain or heart) in appropriate position

Level 4 Two or more internal organs (e.g. stomach and a bone 'unit' such as the ribs) in appropriate positions but no extensive relationships indicated between them

Level 5 One organ system indicated (e.g. gut connecting head to anus)

Level 6 Two or three major organ systems indicated out of skeletal, gaseous exchange, nervous, digestive, endocrine, urinogenital, muscular and circulatory

Level 7 Comprehensive representation with four or more organ systems indicated out of skeletal, gaseous exchange, nervous, digestive, endocrine, urinogenital, muscular and circulatory.

\section{The System Used to Score the Biological Quality of Each Drawing}

Skeletal system

Gaseous exchange system

Nervous system

Digestive system

Endocrine system

Urinogenital system

Muscular system
Skull, spine, ribs and limbs.

Two lungs, two bronchi, windpipe which joins to mouth and/or nose.

Brain, spinal cord, some peripheral nerve(e.g. optic nerve).

Through tube from mouth to anus and indication of convolutions and/or compartmentalisation.

Two endocrine organs (e.g. thyroid, adrenals, pituitary) other than pancreas [scored within digestive system] or gonads [scored within urinogenital system].

Two kidneys, two ureters, bladder and urethra or two ovaries, two fallopian tubes and uterus or two testes, two epididymes and penis.

Two muscle groups (e.g. lower arm and thigh) with attached points of origin. 


\section{Viola Manokore and Michael Reiss}

Circulatory system

Heart, arteries and veins into and/or leaving heart and, at least to some extent, all round the body.

\section{Appendix 1}

Protocol, including the research instrument, used in this study. (At the time of data collection, Michael Reiss was at Homerton College, Cambridge.)

1. Identify suitable schools. You are trying to end up with at least 20 drawings done by 7 year-olds and at least 20 drawings done by 15 year-olds. (If at all possible, it would be nice to have at least 10 drawings at each age range being done by girls and 10 by boys.) The schools to be used should be 'typical' ones for your country so far as this is possible! One school for the 7 year-olds and one school for the 15 year-olds will probably be fine unless you want to get drawings from children in two schools for one or both age groups to try and ensure that you have a representative spread of ch:1dren. In any event, think about such factors as wealth (are the schools in unusually poor or unusually rich districts?), ethnicity (are certain racialgroups not present in the school?), selection/access (is the school feepaying?) and gender (do both boys and girls go to the school)?

2. Get permission (ministry and from each head teacher) to let you go in and do the work.

3. Make arrangements with the teacher in charge of the class for your visit.

4. You will need approximately. 15 minutes with the class. Take in enough white A4 paper (approximately $296 \times 210 \mathrm{~mm}$ ) for each child in the class to have one sheet and for you to have some spare. It may be sensible to take in pencils and pens too or to have checked with the teacher in advance that there will be enough of these for each pupil to have something with which to draw.

5. When you speak to the pupils tell them the following - in whatever language is most appropriate. (You don't need to read this out from a list but do ensure you say all the following in whatever order you feel is appropriate. It is perfectly $\mathrm{OK}$ to repeat instructions but try not to add extra instructions. We want all the countries to have data collected under the same conditions, so far.as this is possible.)

a. I would like each of you to do a drawing of what you think is inside 
yourself.

b. This is not a test or an examination but please don't copy each other's work.

c. You can have as long as you like but I imagine 10-15 minutes should be long enough.

d. This is part of a research project involving lots of children of your age from many countries around the world.

e. Please write your name clearly at the top of the page.

f. Please also write how old you are in years.

g. Please also write whether you are a girl or a boy.

6. If any pupils ask you any questions, try to say 'It's up to you' unless it simply needs you to clarify something you have already said. For example, if they ask you if they should label their drawing say 'It's up to you'; similarly if they ask you how large the drawing should be. If a child tells you that they can't draw, tell them not to worry and that we are interested in what they think is inside themselves not in whether they can draw well.

7. At the end, check that name, age and whether girl/boy is on each drawing, collect in the drawings and thank the children and teacher.

8. Remove any drawings done by pupils who are not 7 years old or 15 years old.

9. If any drawings have labels on them that are not in English, please do a photocopy of the drawing and write an English translation on the photocopy.

10. Write just a few lines about each school. For example: 'Smallwood School has about 700 pupils, both boys and girls, aged from 11 to 16 years-old. About $80 \%$ of pupils are White. The remainder are mainly Asian. Pupils do not need to pay fees to attend and the school is situated in a rural village. The school has a good reputation among parents and academically is fairly typical for a school in England.'

11. Write a few lines about what children at each age group have studied about what is inside themselves. For example: 'By the time they are 15 years old, pupils at Smallwood School have studied the Science National Curriculum in England and Wales since the age of 5. Biology is taught each year as part 
of Science and quite a bit of time is spent on the skeleton, digestive system, the circulatory system, the urinogenital system and gaseous exchange system. Some time, but less, is also spent learning about the nervous system and how muscles work. The only bits of the endocrine system that are studied are the functions of the hormones insulin and adrenaline. Most teaching is done by teachers drawing on the blackboard and by pupils copying from textbooks.' 


\section{(c) (1) (9)}

This work is licensed under a

Creative Commons

Attribution - NonCommercial - NoDerivs 3.0 License.

To view a copy of the license please see:

http://creativecommons.ora/licenses/bv-nc-nd/3.0/ 